\title{
A DITONGAÇÃO DECRESCENTE NA FALA POPULAR DE SALVADOR: análise variacionista
}

Eleneide de Oliveira Silva

(UFBA)

Juliana Ludwig Gayer

(UFBA)

\section{RESUMO}

Este trabalho apresenta uma análise variacionista do processo de ditongação decrescente na fala popular de Salvador. A ditongação pode ocorrer entre palavras, entre a vogal final da primeira palavra e a vogal inicial da segunda palavra na sequência, quando uma das vogais é foneticamente alta e átona. No caso da ditongação decrescente, a segunda vogal se torna glide com a aplicação do processo, como no exemplo minh[aj]scola (minha escola). O objetivo deste trabalho foi contribuir com uma descrição mais detalhada da ditongação decrescente que ocorre no português brasileiro, considerando dados da fala popular de Salvador, retirados do banco PEPP (Programa de Estudos sobre o Português Popular Falado de Salvador), coordenado pela Professora Norma Lopes (UNEB). Selecionamos desse banco de dados oito entrevistas classificadas por sexo (masculino e feminino), escolaridade (fundamental e médio) e idade ( 25 a 35 anos e mais de 65 anos), totalizando 1.121 dados para a análise estatística. Os dados referentes à ditongação decrescente passaram pela análise estatística do Goldvarb X, levando em consideração algumas variáveis já analisadas em outras pesquisas. Os principais fatores favorecedores à aplicação do processo foram combinação de vogal tônica mais vogal átona, domínio do grupo clítico, combinação de vogal não alta mais alta, etc.

PALAVRAS-CHAVE: Variação. Sândi externo. Ditongação decrescente. 


\section{Introdução}

Os processos do português que podem resolver o choque entre núcleos silábicos de palavras diferentes são a elisão, a degeminação e a ditongação, processos conhecidos como sândi externo ou sândi vocálico. Esses processos contribuem para a não formação de hiatos entre palavras, estruturas que são normalmente evitadas em várias línguas, inclusive no português.

A aplicação de cada um dos processos de sândi externo está restrita a determinados contextos. A elisão, por exemplo, ocorre em fronteira de palavras, ou de constituintes maiores, e tem como contexto a combinação de uma vogal baixa/a/ e outra vogal diferente de /a/. Nesse caso, a vogal /a/ é apagada com a aplicação do processo, como no exemplo camis $[e]$ stampada (camisa estampada). A degeminação ocorre quando, entre palavras, há uma sequência de vogais iguais ou semelhantes, as quais são fundidas, como no exemplo cas[a]ntiga (casa antiga). E a ditongação ocorre quando temos, na sequência, uma vogal foneticamente alta e átona, a qual se torna glide com a aplicação do processo, como no exemplo mesm[aj]scova (mesma escova).

No caso da ditongação, encontramos dois tipos de processo. Se a primeira vogal se tornar glide, estamos diante de um caso de ditongação crescente, como em lend[wi]sso (lendo isso). E se a segunda vogal da sequência se tornar glide, temos um caso de ditongação decrescente, como em cois [aj]stranha (coisa estranha). Salientamos que o foco deste trabalho é o processo de ditongação decrescente, no qual a segunda vogal da sequência se torna glide, e para isso ela precisa ser foneticamente alta e átona.

Alguns trabalhos propuseram descrições sobre os fenômenos de sândi externo (Bisol, 1996, 2002; Tenani, 2004; Ludwig-Gayer, 2008) e outros sobre a ditongação especificamente (Brambila, 2015) em português brasileiro, indicando que fatores como acento, domínio prosódico, etc. parecem influenciar a aplicação dos fenômenos.

O objetivo deste trabalho é verificar a relevância dos fatores encontrados nas pesquisas anteriores considerando os contextos de ditongação decrescente e, com isso, contribuir com uma descrição mais detalhada dos fenômenos de sândi que ocorrem no português brasileiro e de seus condicionadores na fala popular de Salvador. Pretendemos comparar nossos resultados com os encontrados em Brambila (2015), que analisou dados 
da cidade de Lages (Santa Catarina), a partir do banco de dados VARSUL. Essa comparação é interessante, pois a metodologia utilizada pelo autor considerou também a subdivisão dos processos de ditongação, separando uma análise apenas para a ditongação crescente e outra para a ditongação decrescente.

\section{A ditongação decrescente}

Vimos que a ditongação decrescente se aplica quando a segunda vogal do hiato se torna glide. Esse processo pode ocorrer no interior de palavra, como vemos no exemplo $s a[w]$ dade (saudade), ou entre palavras, como em mesm[aj]scova (mesma escova).

Além disso, como apenas as vogais altas e átonas podem se tornar glides, pelo menos uma das vogais da sequência deve respeitar essas condições. No caso da ditongação decrescente, a segunda vogal da sequência deve necessariamente ser alta e átona.

Bisol (1996, p. 62) apresenta alguns exemplos para ilustrar a questão da restrição segmental e rítmica que envolve o processo da ditongação. Em verde amarelo, por exemplo, temos duas vogais átonas na fronteira das palavras, [i] e [a], mas apenas uma vogal alta [i], só sendo possível, nesse caso, a aplicação da ditongação crescente: verd[ja]marelo. No caso de duas vogais tônicas, como em revi isso, não temos contexto para a ditongação aplicar, mesmo que as duas vogais sejam altas. Nesse caso, segundo a autora, a ditongação não se aplica, nem a crescente, como em *ver[ji]su, nem a decrescente, como em *rev[ij]su.

\section{Metodologia $^{1}$}

Os dados referentes à ditongação que foram considerados nesta pesquisa passaram pela análise estatística do programa Goldvarb X. Este tipo de análise, assim como a análise a partir do pacote de programas Varbrul, envolve os seguintes aspectos: definição da variável dependente, definição das variáveis independentes, delimitação da amostra, obtenção dos dados, transcrição, codificação e quantificação dos dados e interpretação dos resultados (Brescancini, 2002).

A variável dependente analisada nesta pesquisa compreende a aplicação ou a não aplicação da regra variável da ditongação decrescente, como nos exemplos: $j[a j]$ stava (aplicação) e $j[a][e]$ stava (não aplicação). As variáveis independentes foram constituídas com base nos modelos de Ludwig-Gayer (2008) e Brambila (2015), que consideraram os 
resultados encontrados em outras pesquisas sobre o fenômeno. A partir desses modelos, alguns ajustes foram feitos e as seguintes variáveis linguísticas independentes foram selecionadas.

\author{
Acento \\ $\mathrm{V}$ átona $+\mathrm{V}$ átona (minha infância) \\ $\mathrm{V}$ átona $+\mathrm{V}$ tônica (nuclear) (tinha ido) \\ $\mathrm{V}$ átona $+\mathrm{V}$ tônica (não-nuclear) (pego uma) \\ $\mathrm{V}$ tônica $+\mathrm{V}$ átona (já estava) \\ $\mathrm{V}$ tônica $+\mathrm{V}$ tônica (né isso)

\section{Domínio prosódico} \\ Grupo clítico (no estádio) \\ Frase (nossa infração) \\ Enunciado (maior do que a frase) (caminha e)

\section{Extensão do vocábulo} \\ Qualquer extensão (tudo isso) \\ $\mathrm{V}+\ldots($ a igreja $)$ \\ ... $+\mathrm{V}($ escola e $)$
}

\title{
Distância entre os acentos
}

Acentos adjacentes (até um)

1 sílaba (lá então)

2 sílabas (da escola)

+ 2 sílabas (quando interessa)

\section{Combinação de palavras}

funcional + não-funcional (uma informação)

não-funcional + funcional (discipulo um)

funcional + funcional (de um)

não-funcional + não-funcional (igreja universal)

\section{Estrutura silábica de V2}

sílaba aberta (minha igreja)

sílaba fechada (no estádio) 
Categoria de V2: altura

Alta + alta (diferentes) (eu ia)

Alta + não-alta (mordeu aqui)

Não-alta + alta (na igreja)

Não-alta + /e/ ou /o/ (saltava em)

/e/ ou /o/ finais + alta (tudo isso)

/e/ ou /o/ finais + não-alta (quatro anos)

\section{Categoria de V2: posterioridade}

Anterior + posterior (comprei um)

Anterior + central (estudei ali)

Anteriores (pai e)

Posteriores (do Uruguai)

Posterior + anterior (meu irmão)

Posterior + central (botou aquele)

Central + posterior ( a unidade)

Central + anterior (a idade)

\section{Contexto precedente}

Vogal (comprei um)

Semivogal (família e)

Consoante (quando um)

Vazio (a igreja)

\section{Contexto seguinte}

Vogal (eu ia)

Semivogal (sou eu)

Consoante (dando escolha)

Vazio (leva o)

\subsection{Hipóteses e perguntas adicionais}

Depois de apresentarmos nossas variáveis linguísticas independentes, podemos resumir as principais hipóteses que serviram de ponto de partida para a posterior análise, todas elas baseadas nos resultados de Ludwig-Gayer (2008), que encontrou contextos para a aplicação da ditongação diferentes dos encontrados para a elisão e a degeminação. Segundo a autora, "a elisão e a degeminação parecem ser favorecidas em alguns 
contextos, ao passo que a ditongação em outros; ou seja, nos contextos em que a EL e a DE se aplicam com mais frequência, a DI parece não se aplicar normalmente, e vice-versa” (Ludwig-Gayer, 2008, p. 83). Considerando esses resultados, partimos das seguintes hipóteses neste trabalho:

O grupo clítico será o domínio preferencial para a aplicação da ditongação;

O contexto ideal para a ditongação será constituído de pelo menos uma vogal tônica na sequência;

A ditongação será favorecida quando sua aplicação gerar choque de acentos;

Espera-se um padrão de variação estável, no qual fatores como sexo, idade e escolaridade não tenham papel.

Assim como Ludwig-Gayer (2008), também consideramos duas perguntas adicionais para verificação. A primeira diz respeito a uma observação encontrada no catalão (Cabré e Prieto, 2005). Nessa língua, quando a segunda vogal ocorre em uma sílaba fechada, seu apagamento é favorecido. Será que o fato de a segunda vogal ocorrer numa sílaba aberta ou fechada pode influenciar também no caso da ditongação?

A segunda pergunta também está baseada em observações do catalão, em que foi constatado que a presença de uma palavra funcional favorece o apagamento de uma das vogais. Será que a presença de uma palavra funcional na sequência pode influenciar também os casos de ditongação do português?

\subsection{Amostra}

O corpus analisado nesta pesquisa foi coletado a partir de oito entrevistas da cidade de Salvador que compõem o banco de dados PEPP (Programa de Estudos sobre o Português Popular Falado de Salvador), coordenado pela Professora Norma Lopes (UNEB). A distribuição dos informantes foi regulada pelas variáveis sexo, idade e escolaridade. Dessa forma, selecionamos quatro informantes de cada sexo, de cada faixa etária e de cada grau de escolaridade, como podemos visualizar no esquema a seguir: 
Homem

Mulher

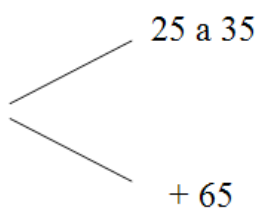

fundamental informante 40

médio informante 13

fundamental informante 34

médio informante 14

fundamental informante 19

médio informante 23

fundamental informante 01

médio informante 41

Em uma primeira análise das transcrições ortográficas das entrevistas, encontramos um total de 6.571 contextos propícios à ditongação, sendo que para cada informante encontramos os seguintes contextos:

Quadro 1 - Distribuição de dados por informante (sem recorte)

\begin{tabular}{|c|c|}
\hline informante 01 & 680 \\
\hline informante 13 & 900 \\
\hline informante 14 & 887 \\
\hline informante 19 & 978 \\
\hline informante 23 & 874 \\
\hline informante 34 & 756 \\
\hline informante 40 & 726 \\
\hline informante 41 & 770 \\
\hline TOTAL & 6.571 \\
\hline
\end{tabular}

Depois de encontrarmos esses 6.571 contextos, fizemos um primeiro recorte, selecionando 1.495 dados para a análise estatística. Esse recorte foi feito considerando aproximadamente dez dados de cada contexto para cada informante. Nos casos em que tínhamos menos de dez dados, foi selecionada a quantidade existente, como mostra o quadro a seguir: 
Quadro 2 - Distribuição de dados por contexto e informante (primeiro recorte)

\begin{tabular}{|c|c|c|c|c|c|c|c|c|}
\hline Contextos & Inf 1 & $\begin{array}{l}\text { Inf } \\
13\end{array}$ & $\begin{array}{l}\text { Inf } \\
14\end{array}$ & $\begin{array}{l}\text { Inf } \\
19\end{array}$ & $\begin{array}{l}\text { Inf } \\
23\end{array}$ & $\begin{array}{l}\text { Inf } \\
34\end{array}$ & $\begin{array}{l}\text { Inf } \\
40\end{array}$ & $\begin{array}{l}\text { Inf } \\
41\end{array}$ \\
\hline $\mathbf{a} \# \mathbf{e}$ & 10 & 10 & 10 & 10 & 10 & 10 & 10 & 10 \\
\hline $\mathbf{a} \# \mathbf{i}$ & 10 & 10 & 10 & 10 & 10 & 10 & 10 & 10 \\
\hline a\#o & 10 & 10 & 10 & 10 & 10 & 10 & 10 & 10 \\
\hline $\mathbf{a \# \mathbf { u }}$ & 10 & 10 & 10 & 10 & 10 & 10 & 10 & 10 \\
\hline e\#i & 10 & 10 & 10 & 10 & 10 & 10 & 10 & 10 \\
\hline e\#o & 10 & 10 & 10 & 10 & 10 & 10 & 10 & 10 \\
\hline e\#a & 10 & 10 & 10 & 10 & 10 & 10 & 10 & 10 \\
\hline $\mathbf{e} \# \mathbf{u}$ & 10 & 10 & 10 & 10 & 10 & 10 & 10 & 10 \\
\hline $\mathbf{i} \# \mathbf{a}$ & 10 & 10 & 10 & 10 & 10 & 10 & 10 & 10 \\
\hline i\#o & 4 & 2 & 10 & 7 & 7 & 10 & 6 & 6 \\
\hline i\#u & 6 & 10 & 9 & 10 & 10 & 3 & 6 & 7 \\
\hline i\#e & 10 & 10 & 10 & 10 & 10 & 10 & 10 & 10 \\
\hline $\mathbf{o \# \mathbf { u }}$ & 2 & 10 & 10 & 10 & 4 & 10 & 8 & 10 \\
\hline o\#a & 10 & 10 & 10 & 10 & 10 & 10 & 10 & 10 \\
\hline o\# & 10 & 10 & 10 & 10 & 10 & 10 & 10 & 10 \\
\hline o\#i & 10 & 10 & 10 & 10 & 10 & 10 & 10 & 10 \\
\hline $\mathbf{u} \# \mathbf{o}$ & 2 & 3 & 4 & 10 & 7 & 10 & 10 & 8 \\
\hline $\mathbf{u} \# \mathbf{a}$ & 10 & 10 & 10 & 10 & 10 & 10 & 10 & 10 \\
\hline $\mathbf{u \# \mathbf { e }}$ & 10 & 10 & 10 & 10 & 10 & 10 & 10 & 10 \\
\hline $\mathbf{u} \# \mathbf{i}$ & 10 & 4 & 9 & 10 & 10 & 2 & 9 & 10 \\
\hline total & 174 & 179 & 192 & 197 & 188 & 185 & 189 & 191 \\
\hline
\end{tabular}

A partir desse primeiro recorte, chegamos a um total de 1.495 dados, mas nos deparamos com alguns casos problemáticos, como os que tinham glide na fronteira da palavra, como em pa[j] azarado. Resolvemos tirar também esses casos, pois acreditamos que isso não indicaria que o processo foi aplicado pelo choque dos núcleos de palavras diferentes, visto que o glide já está na fronteira da palavra antes mesmo de as palavras ficarem adjacentes. Depois deste último recorte, então, restaram 
1.121 dados para a análise estatística, divididos entre os informantes da seguinte forma:

\section{Quadro 3 - Distribuição de dados por informante (último recorte)}

\begin{tabular}{|c|c|}
\hline informante 01 & 133 \\
\hline informante 13 & 134 \\
\hline informante 14 & 149 \\
\hline informante 19 & 143 \\
\hline informante 23 & 135 \\
\hline informante 34 & 146 \\
\hline informante 40 & 137 \\
\hline informante 41 & 144 \\
\hline TOTAL & 1.121 \\
\hline
\end{tabular}

Os dados selecionados nesse último recorte passaram pela análise estatística do programa Goldvarb X. Nessa análise, fizemos duas rodadas, a fim de separar os grupos de fatores não ortogonais. Na primeira rodada, os grupos de fatores considerados foram acento, domínio prosódico, extensão do vocábulo, estrutura silábica de V2, categoria das vogais: altura e posterioridade, contexto precedente, contexto seguinte, sexo, idade e escolaridade. Na segunda rodada, consideramos os grupos extensão do vocábulo, distância entre os acentos, combinação de palavras, estrutura silábica de V2, categoria das vogais: altura e posterioridade, contexto seguinte, contexto precedente e informante.

\section{Descrição e análise dos resultados}

A ditongação decrescente apresentou uma porcentagem de aplicação de $12 \%$ nos dados de Salvador, taxa diferente da encontrada em Brambila (2015), que constatou $60,6 \%$ de aplicação da ditongação decrescente em Lages (SC).

\subsection{Resultados da primeira rodada}

Na primeira rodada, as variáveis selecionadas pelo programa como relevantes à ditongação decrescente foram as seguintes, apresentadas de acordo com a ordem de seleção do próprio programa. 
Tabela 1

\begin{tabular}{|c|c|c|c|}
\hline \multicolumn{4}{|c|}{ ACENTO $^{1}$} \\
\hline FATORES & $\begin{array}{l}\text { APLIC/ } \\
\text { TOTAL }\end{array}$ & $\%$ & $\begin{array}{c}\text { PESO } \\
\text { RELATIVO }\end{array}$ \\
\hline $\begin{array}{c}\text { TÔNICA + } \\
\text { ÁTONA } \\
\text { (tá } \\
\text { entendendo) }\end{array}$ & $36 / 129$ & 28 & 0.99 \\
\hline $\begin{array}{c}\text { ÁTONA + } \\
\text { ÁTONA } \\
\text { (o esporte) }\end{array}$ & 98/496 & 20 & 0.82 \\
\hline $\begin{array}{c}\text { ÁTONA + } \\
\text { TÔNICA } \\
\text { (NÃO } \\
\text { NUCLEAR) } \\
\text { (era uma } \\
\text { pessoa) }\end{array}$ & $1 / 345$ & 0.3 & 0.02 \\
\hline TOTAL & $135 / 970$ & 14 & \\
\hline
\end{tabular}

INPUT: 0.043

SIGNIFICÂNCIA: 0.000

De acordo com os resultados da Tabela 1, os fatores tônica + átona e átona + átona parecem favorecer a ditongação decrescente, com pesos relativos de 0.99 e 0.82 , respectivamente. Já o fator átona + tônica (não nuclear) mostrou não favorecer a ditongação decrescente, com peso relativo de 0.02 .

Em Brambila (2015), o fator tônica + átona também revelou ser o mais favorecedor à regra da ditongação decrescente, apresentando um peso relativo de 0.69 , enquanto o fator átona + tônica apresentou um peso relativo de 0.24 . 
Tabela 2

DOMÍNIO PROSÓDICO

\begin{tabular}{c|c|c|c}
\hline FATORES & APLIC/TOTAL & $\%$ & $\begin{array}{c}\text { PESO } \\
\text { RELATIVO }\end{array}$ \\
\hline $\begin{array}{c}\text { GRUPO } \\
\text { CLÍTICO } \\
\text { (a igreja) }\end{array}$ & $\mathbf{8 3 / 2 9 4}$ & $\mathbf{2 8}$ & $\mathbf{0 . 9 6}$ \\
\hline $\begin{array}{c}\text { FRASE } \\
\text { FONOLÓGICA } \\
\text { (ela empinava) }\end{array}$ & $\mathbf{5 0 / 5 4 8}$ & $\mathbf{9}$ & $\mathbf{0 . 3 6}$ \\
\hline $\begin{array}{c}\text { ENUNCIADO } \\
\text { conhecimento } \\
\text { em termos) }\end{array}$ & $\mathbf{2 / 2 7 9}$ & $\mathbf{0 . 7}$ & $\mathbf{0 . 0 9}$ \\
\hline \begin{tabular}{c} 
TOTAL \\
\hline
\end{tabular}
\end{tabular}

INPUT: 0.043

SIGNIFICÂNCIA: 0.000

Nos resultados da Tabela 2, o fator grupo clítico demonstrou favorecer a regra, com peso relativo de 0.96 , enquanto o fator enunciado, com peso relativo de 0.09, parece ser não favorecedor. Em Brambila (2015), esse grupo de fator não foi selecionado para a ditongação decrescente.

Tabela 3

CATEGORIA DAS VOGAIS: ALTURA ${ }^{2}$

\begin{tabular}{c|c|c|c}
\hline FATORES & $\begin{array}{c}\text { APLIC/ } \\
\text { TOTAL }\end{array}$ & $\%$ & $\begin{array}{c}\text { PESO } \\
\text { RELATIVO }\end{array}$ \\
\hline $\left.\begin{array}{c}\text { NÃO ALTA }+ \\
\text { ALTA } \\
(\text { veja o }\end{array}\right)$ & $\mathbf{6 6 / 2 7 4}$ & $\mathbf{2 4}$ & $\mathbf{0 . 5 6}$ \\
\hline $\begin{array}{c}\text { ALTAS } \\
\text { DIFERENTES } \\
(\text { no início })\end{array}$ & $\mathbf{6 9 / 2 6 3}$ & $\mathbf{2 6}$ & $\mathbf{0 . 4 3}$ \\
\hline TOTAL & $\mathbf{1 3 5 / 5 3 7}$ & $\mathbf{2 5}$ & \\
\hline
\end{tabular}

INPUT: 0.043

SIGNIFICÂNCIA: 0.000 
No grupo de fator categoria das vogais: altura, o fator não alta + alta apresentou o peso relativo 0.56 , mostrando favorecer a aplicação da regra, e o fator altas diferentes, com peso relativo 0.43 , não favorece a aplicação.

Em Brambila (2015), o fator que demonstrou favorecer mais a ditongação decrescente foi vogal não alta $+/ \mathrm{e} / \mathrm{ou} / \mathrm{o} /$, com peso relativo de 0.68 , já o fator vogal alta + vogal não alta revelou pouco favorecimento da regra, com peso relativo de 0.02 .

Tabela 4

ESCOLARIDADE

\begin{tabular}{c|c|c|c}
\hline FATORES & APLIC/TOTAL & $\%$ & $\begin{array}{c}\text { PESO } \\
\text { RELATIVO }\end{array}$ \\
\hline FUNDAMENTAL & $\mathbf{6 7 / 5 5 9}$ & $\mathbf{1 2}$ & $\mathbf{0 . 5 5}$ \\
\hline MÉDIO & $\mathbf{6 8 / 5 6 2}$ & $\mathbf{1 2}$ & $\mathbf{0 . 4 5}$ \\
\hline TOTAL & $\mathbf{1 3 5 / 1 1 2 1}$ & $\mathbf{1 2}$ & \\
\hline
\end{tabular}

INPUT: 0.043

SIGNIFICÂNCIA: 0.000

Nos resultados do grupo de fatores escolaridade, apesar de os pesos estarem próximos ao ponto neutro, podemos dizer que o fator fundamental apresentou o peso relativo de 0.55 , mostrando ser favorecedor, enquanto o fator médio, com peso de 0.45 , parece não favorecer.

Em Brambila (2015), o fator secundário revelou favorecer mais a ditongação decrescente, com peso relativo de 0.62 , diferentemente do fator primário, que apresentou peso relativo de 0.39 , mostrando não favorecer a regra.

\subsection{Resultados da segunda rodada}

As variáveis selecionadas pelo programa como relevantes à ditongação decrescente, na segunda rodada, foram as que seguem. Aqui consideramos a ordem de seleção do programa e as variáveis ainda não apresentadas na primeira rodada. 


\section{Tabela 5}

CATEGORIA DAS VOGAIS: POSTERIORIDADE ${ }^{4}$

\begin{tabular}{c|c|c|c}
\hline FATORES & $\begin{array}{c}\text { APLIC/ } \\
\text { TOTAL }\end{array}$ & $\%$ & $\begin{array}{c}\text { PESO } \\
\text { RELATIVO }\end{array}$ \\
\hline $\begin{array}{c}\text { Anterior }+ \\
\text { posterior } \\
\text { (se o) }\end{array}$ & $\mathbf{4 7 / 1 9 9}$ & $\mathbf{2 4}$ & $\mathbf{0 . 7 7}$ \\
\hline $\begin{array}{c}\text { Posterior }+ \\
\text { anterior } \\
\text { (o estudo) }\end{array}$ & $\mathbf{3 0 / 1 6 1}$ & $\mathbf{1 9}$ & $\mathbf{0 . 5 9}$ \\
\hline $\begin{array}{c}\text { Anteriores } \\
\text { (aí então) }\end{array}$ & $\mathbf{3 / 1 5 7}$ & $\mathbf{2}$ & $\mathbf{0 . 5 6}$ \\
\hline $\begin{array}{c}\text { Central }+ \\
\text { anterior } \\
\text { (pra escola) }\end{array}$ & $\mathbf{5 0 / 1 6 0}$ & $\mathbf{3 1}$ & $\mathbf{0 . 4 8}$ \\
\hline $\begin{array}{c}\text { Central }+ \\
\text { posterior } \\
\text { (passava os) }\end{array}$ & $\mathbf{5 / 1 6 0}$ & $\mathbf{3}$ & $\mathbf{0 . 1 2}$ \\
\hline TOTAL & $\mathbf{1 3 5 / 8 3 7}$ & $\mathbf{1 6}$ & \\
\hline
\end{tabular}

INPUT: 0.118

SIGNIFICÂNCIA: 0.048

Nos resultados apresentados na Tabela 5, o fator anterior + posterior demonstrou favorecer a aplicação da ditongação decrescente, com peso relativo de 0.77 ; e o fator posterior + anterior mostrou favorecer também a aplicação da regra, com um peso relativo de 0.59. Já o fator central + posterior demonstrou não favorecer a aplicação da regra, com um peso relativo de 0.12 .

Em Brambila (2015), a ditongação decrescente mostrou ser mais favorecida no fator vogal anterior + vogal posterior, com peso relativo de 0.64 , assim como nos nossos dados, mas o fator vogal posterior + vogal anterior pareceu não favorecer a regra, com peso relativo de 0.17 . 
Tabela 6

\begin{tabular}{c|c|c|c}
\multicolumn{4}{c}{ COMBINAÇÃO DE PALAVRAS } \\
\hline FATORES & $\begin{array}{c}\text { APLIC/ } \\
\text { TOTAL }\end{array}$ & $\%$ & $\begin{array}{c}\text { PESO } \\
\text { RELATIVO }\end{array}$ \\
\hline $\begin{array}{c}\text { Funcional + } \\
\text { não funcional } \\
\text { (quando } \\
\text { interessa) }\end{array}$ & $\mathbf{7 1 / 2 8 8}$ & $\mathbf{2 5}$ & $\mathbf{0 . 8 8}$ \\
\hline $\begin{array}{c}\text { Funcional }+ \\
\text { funcional } \\
\text { (para o) }\end{array}$ & $\mathbf{4 6 / 3 5 5}$ & $\mathbf{1 3}$ & $\mathbf{0 . 6 0}$ \\
\hline $\begin{array}{c}\text { Não funcional } \\
+ \text { não } \\
\text { funcional } \\
\text { (coisa } \\
\text { estranha) }\end{array}$ & $\mathbf{6 / 1 1 8}$ & $\mathbf{5}$ & $\mathbf{0 . 4 1}$ \\
\hline $\begin{array}{c}\text { Não funcional } \\
+ \text { funcional } \\
\text { (veja o) }\end{array}$ & $\mathbf{1 2 / 3 6 0}$ & $\mathbf{3}$ & $\mathbf{0 . 1 3}$ \\
\hline \begin{tabular}{c} 
TOTAL \\
\hline
\end{tabular} & $\mathbf{1 3 5 / 1 1 2 1}$ & $\mathbf{1 2}$ & \\
\hline
\end{tabular}

INPUT: 0.118

SIGNIFICÂNCIA: 0.048

De acordo com os resultados da Tabela 6, os fatores funcional + não funcional e funcional + funcional parecem ser favorecedores à aplicação da ditongação decrescente, com os pesos relativos 0.88 e 0.60 , respectivamente. $\mathrm{O}$ fator não funcional + funcional apresentou peso relativo de 0.13, mostrando não favorecer a aplicação da regra. Em Brambila (2015), esse grupo de fator não foi selecionado para a ditongação decrescente. 


\section{Tabela 7}

EXTENSÃO DO VOCÁBULO

\begin{tabular}{c|c|c|c}
\hline FATORES & APLIC/TOTAL & $\%$ & $\begin{array}{c}\text { PESO } \\
\text { RELATIVO }\end{array}$ \\
\hline $\begin{array}{c}\text { Vogal + vogal } \\
\text { (e o) }\end{array}$ & $\mathbf{6} / \mathbf{1 5}$ & $\mathbf{4 0}$ & $\mathbf{0 . 9 6}$ \\
\hline $\begin{array}{c}\text { Vogal + palavra } \\
\text { (a igreja) }\end{array}$ & $\mathbf{3 4 / 1 1 3}$ & $\mathbf{3 0}$ & $\mathbf{0 . 8 1}$ \\
\hline $\begin{array}{c}\text { Palavra + vogal } \\
\text { (senhorita o) }\end{array}$ & $\mathbf{3 8 / 2 1 2}$ & $\mathbf{1 8}$ & $\mathbf{0 . 8 0}$ \\
\hline $\begin{array}{c}\text { Qualquer } \\
\text { extensão } \\
\text { (capitalista } \\
\text { influencia) }\end{array}$ & $\mathbf{5 7 / 7 8 1}$ & $\mathbf{7}$ & $\mathbf{0 . 3 4}$ \\
\hline \multicolumn{1}{c|}{ TOTAL } & $\mathbf{1 3 5 / 1 1 2 1}$ & $\mathbf{1 2}$ & \\
\hline
\end{tabular}

INPUT: 0.118

SIGNIFICÂNCIA: 0.048

No grupo de fator extensão do vocábulo, o fator vogal + vogal demonstrou favorecer bastante a aplicação da regra, com o peso relativo de 0.96 , e os fatores vogal + palavra e palavra + vogal também parecem favorecer a regra, com pesos relativos de 0.81 e 0.80 , respectivamente. Já o fator qualquer extensão apresentou o peso relativo de 0.34 , indicando não favorecer a regra.

Em Brambila (2015), o fator vogal + qualquer extensão revelou favorecer mais a ditongação decrescente, com o peso relativo 0.74 , já o fator qualquer extensão + vogal revelou favorecer menos a regra, com peso relativo de 0.38 , distanciando-se um pouco dos nossos resultados. 


\section{Tabela 8}

DISTANCIA ENTRE ACENTOS 5

\begin{tabular}{c|c|c|c}
\hline FATORES & $\begin{array}{c}\text { APLIC/ } \\
\text { TOTAL }\end{array}$ & $\%$ & $\begin{array}{c}\text { PESO } \\
\text { RELATIVO }\end{array}$ \\
\hline $\begin{array}{c}\text { Mais de duas } \\
\text { sílabas } \\
\text { (quando } \\
\text { interessa) }\end{array}$ & $\mathbf{2 5 / 1 3 2}$ & $\mathbf{1 9}$ & $\mathbf{0 . 6 5}$ \\
\hline $\begin{array}{c}\text { Duas sílabas } \\
\text { (da escola) }\end{array}$ & $\mathbf{7 5 / 3 3 7}$ & $\mathbf{2 2}$ & $\mathbf{0 . 6 1}$ \\
\hline $\begin{array}{c}\text { Uma sílaba } \\
\text { (lá então) }\end{array}$ & $\mathbf{3 5 / 5 3 7}$ & $\mathbf{6}$ & $\mathbf{0 . 3 9}$ \\
\hline TOTAL & $\mathbf{1 3 5 / 1 0 0 6}$ & $\mathbf{1 3}$ & \\
\hline
\end{tabular}

INPUT: 0.118

SIGNIFICÂNCIA: 0.048

No grupo de fator distância entre os acentos, o fator mais de duas sílabas demonstrou ser favorecedor à regra, com peso relativo de 0.65 , e o fator duas sílabas também parece favorecer a aplicação da ditongação decrescente, com peso relativo de 0.61 . Já o fator uma sílaba demonstrou não favorecer a aplicação da regra, com peso relativo 0.39 .

No trabalho de Brambila (2015), o fator distância de duas sílabas revelou favorecer a ditongação decrescente, com peso relativo de 0.61 , resultado igual ao encontrado nesta pesquisa, enquanto o fator distância de uma sílaba apresentou o peso relativo de 0.35 , também próximo ao resultado encontrado neste trabalho. 
Tabela 9

CONTEXTO PRECEDENTE6

\begin{tabular}{c|c|c|c}
\hline FATORES & $\begin{array}{c}\text { APLIC/ } \\
\text { TOTAL }\end{array}$ & $\%$ & $\begin{array}{c}\text { PESO } \\
\text { RELATIVO }\end{array}$ \\
\hline $\begin{array}{c}\text { Vogal } \\
\text { (cria os) }\end{array}$ & $\mathbf{1 4 / 1 1 3}$ & $\mathbf{1 2}$ & $\mathbf{0 . 8 0}$ \\
\hline $\begin{array}{c}\text { Consoante } \\
\text { (Fora os) }\end{array}$ & $\mathbf{8 1 / 8 7 2}$ & $\mathbf{9}$ & $\mathbf{0 . 4 8}$ \\
\hline $\begin{array}{c}\text { Vazio } \\
\text { (a escola) }\end{array}$ & $\mathbf{4 0 / 1 2 8}$ & $\mathbf{3 1}$ & $\mathbf{0 . 3 1}$ \\
\hline \multicolumn{1}{c}{} & $\mathbf{1 3 5 / 1 1 1 3}$ & $\mathbf{1 2}$ & \\
\hline
\end{tabular}

INPUT: 0.118

SIGNIFICÂNCIA: 0.048

De acordo com os resultados da Tabela 9, o fator vogal demonstrou ser favorecedor à ditongação decrescente, com o peso relativo de 0.80 , e o fator vazio parece não favorecer a aplicação da regra, com peso relativo de 0.31. Em Brambila (2015), esse grupo de fator não foi selecionado para a ditongação decrescente.

Tabela 10

INFORMANTE

\begin{tabular}{|c|c|c|c|}
\hline FATORES & APLIC/TOTAL & $\%$ & $\begin{array}{c}\text { PESO } \\
\text { RELATIVO }\end{array}$ \\
\hline $\begin{array}{c}\text { INFORMANTE } \\
41 \\
(\mathrm{M}-\mathrm{V}-\mathrm{EM})\end{array}$ & $26 / 144$ & 18 & 0.69 \\
\hline $\begin{array}{c}\text { INFORMANTE } \\
\begin{array}{c}34 \\
(H-V-E F)\end{array}\end{array}$ & $22 / 146$ & 15 & 0.61 \\
\hline $\begin{array}{c}\text { INFORMANTE } \\
1 \\
(\mathrm{M}-\mathrm{V}-\mathrm{EF})\end{array}$ & $16 / 133$ & 12 & 0.55 \\
\hline $\begin{array}{c}\text { INFORMANTE } \\
\begin{array}{c}19 \\
(\mathrm{M}-\mathrm{N}-\mathrm{EF})\end{array}\end{array}$ & $14 / 143$ & 10 & 0.50 \\
\hline
\end{tabular}




\begin{tabular}{c|c|c|c}
\hline $\begin{array}{c}\text { INFORMANTE } \\
13\end{array}$ & $13 / 134$ & 10 & 0.46 \\
\hline $\begin{array}{c}\text { INFORMANTE }- \text { EM) } \\
23\end{array}$ & $13 / 135$ & 10 & 0.42 \\
$\left(\begin{array}{c}\text { M }- \text { EM) } \\
\text { INFORMANTE } \\
14\end{array}\right.$ & $16 / 149$ & 11 & 0.38 \\
$($ H - V - EM) & & & \\
\hline $\begin{array}{c}\text { INFORMANTE } \\
40\end{array}$ & $15 / 137$ & 11 & 0.38 \\
$(H-N-$ EF $)$ & $135 / 1121$ & 12 & \\
\hline TOTAL & & &
\end{tabular}

INPUT: 0.118

SIGNIFICÂNCIA: 0.048

Nos resultados da Tabela 10, o informante 41 mostrou favorecer a aplicação da regra, apresentando um peso relativo de 0.69 , e o informante 34 também parece favorecer a regra, com o peso relativo de 0.61. Já os informantes 14 e 40 revelaram não favorecer a aplicação da ditongação decrescente, apresentando ambos um peso relativo de 0.38 .

\section{Considerações finais}

As rodadas dos dados no programa Goldvarb X nos indicaram que o processo de ditongação decrescente parece ser mais aplicado nos seguintes contextos: quando temos a combinação de vogal tônica mais vogal átona, no domínio do grupo clítico, quando temos vogal não alta mais vogal alta, na combinação de vogal anterior mais vogal posterior, entre palavras funcionais mais não funcionais, na combinação de vogal mais vogal, quando há duas ou mais sílabas entre os acentos, quando o contexto precedente é uma vogal, e alguns informantes parecem aplicar mais a regra do que outros.

Considerando esses contextos favoráveis à aplicação do processo, podemos confirmar algumas de nossas hipóteses. Em relação à primeira hipótese, por exemplo, percebemos que o constituinte grupo clítico demonstrou ser o domínio preferencial para a aplicação da ditongação decrescente, confirmando essa hipótese e aproximando os nossos resultados 
aos encontrados em Ludwig-Gayer (2008).

A nossa segunda hipótese também foi confirmada, pois o fator vogal tônica + vogal átona demonstrou ser favorecedor à ditongação decrescente. E a hipótese de favorecimento do processo no caso de sua aplicação gerar choque de acentos não foi confirmada, visto que o fator que apresentou menor peso relativo (0.39) foi a distância de uma sílaba entre os acentos, ou seja, quando a aplicação da ditongação gera choque de acentos, a regra não é favorecida.

Em relação à nossa quarta hipótese, apesar de o programa selecionar o grupo de fator escolaridade, os pesos relativos se encontram próximos ao ponto neutro, o que parece indicar que, na verdade, o grupo escolaridade pode não ter papel e podemos considerar que ainda estamos diante de um processo de variação estável.

Sobre as perguntas adicionais, podemos considerar o seguinte: (1) o grupo de fator da estrutura silábica não foi selecionado pelo programa na análise da ditongação decrescente; (2) a presença de uma palavra funcional na sequência parece favorecer a aplicação da ditongação decrescente, pois o fator funcional mais não funcional demonstrou favorecer a regra, com peso relativo de 0.88 , indicando que a presença de uma palavra funcional pode estar influenciando a aplicação da ditongação no português. Para termos certeza, precisaríamos fazer alguns cruzamentos e verificar se é o fato de a palavra ser funcional que está influenciando a regra ou a questão da extensão do vocábulo (ou ainda outro fator). 


\section{THE DECREASED DIPHTHONGIZATION \\ IN POPULAR SPEECH OF SALVADOR: VARIATIO- NAL ANALYSIS}

\section{ABSTRACT}

This work presents a variational analysis of the decreased diphthongization process in the popular speech of Salvador. The diphthongization can occur between words, between the final vowel of the first word and the initial vowel of the second word in the sequence, when one of the vowels is phonetically high and unstressed. In the case of decreased diphthongization, the second vowel becomes glide with the application of the process, as in the example $\operatorname{minh}[a j]$ scola (my school). The objective of this work was to contribute with a more detailed description of the decreased diphthongization that occurs in Brazilian Portuguese, considering the popular speech data of Salvador, taken from PEPP (Studies Program on the Spoken Popular Portuguese of Salvador), coordinated by Professor Norma Lopes (UNEB). We selected eight interviews classified by sex (male and female), education (primary and secondary education) and age (25-35 years and over 65 years), totaling 1.121 data for the statistical analysis. These data passed through a statistical analysis of Goldvarb $\mathrm{X}$, taking into account some variables that have already been analysed in other studies. The main favorable factors to the application of the process were a combination of a stressed vowel plus an unstressed vowel, clitic group, combination of a not high vowel plus a high vowel, etc.

KEYWORDS: Variation. External sandhi. Decreased diphthongization. 


\section{REFERÊNCIAS}

BRAMBILA, T. Análise variacionista da ditongação como processo de sândi externo na fala de Lages/Santa Catarina. Dissertação (mestrado), Universidade Federal do Rio Grande do Sul, 2015.

BISOL, L. A degeminação e a elisão no VARSUL. In: BISOL, L.; BRESCANCINI, C. (orgs.) Fonologia e variação: recortes do português brasileiro. Porto Alegre: EDIPUCRS, 2002. p. 231-250.

BISOL, L. Os constituintes prosódicos. In: BISOL, Leda (org.). Introdução a estudos de fonologia do português brasileiro. $4^{\mathrm{a}}$ ed. Porto Alegre: EDIPUCRS, 2005. p. 243-255.

BISOL, L. Sândi externo: O processo e a variação. In: KATO, M. (org.) Gramática do português falado. Volume V: convergências. $2^{\mathrm{a}}$ ed. Campinas, SP. Editora da UNICAMP, 1996. p. 53-97.

BRESCANCINI, C. A análise de regra variável e o programa VARBRUL 2S. In: BISOL, L.; BRESCANCINI, C. (orgs.) Fonologia e variação: recortes do português brasileiro. Porto Alegre: EDIPUCRS, 2002. p. 13-75.

CABRÉ, T.; PRIETO, P. Positional and metrical prominence effects on vowel sandhi in Catalan. In: FROTA, S.; VIGÁRIO, M.; FREITAS, M. J (ed.) Prosodies - with special reference to Iberian languages. Berlim: Mouton de Gruyter, 2005. p. 123-157.

COLLISCHONN, G. A sílaba em português. In: BISOL, L. (org). Introdução a estudos de fonologia do português brasileiro. $4^{\mathrm{a}}$ ed. Porto Alegre: EDIPUCRS, 2005. p. 101-133.

FREITAG, R; MITTMANN, M. Goldvarb 2001: comandos e recursos da ferra-

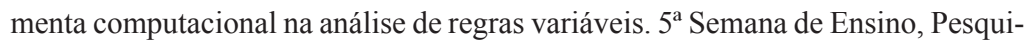
sa e Extensão da UFSC, 2005.

LABOV, W. The social motivation of a sound change. In: Sociolinguistic patterns. Philadelphia: University of Pennsylvania Press, 1972. p. 1-42.

LUDWIG-GAYER, J. Os processos de sândi externo: análise variacionista da fala de São Borja. Dissertação (mestrado), Universidade Federal do Rio Grande do Sul, 2008.

MATEUS, M. H.; D'ANDRADE, E. Phonological processes. In: The phonology of portuguese. New York: Oxford, 2000. p. 129-148.

NARO, A. Modelos quantitativos e tratamento estatístico. In: MOLLICA, M; BRAGA, M. Introdução à sociolinguística: o tratamento da variação. São Paulo: Contexto, 2004. p. 15-25. 
SILVEIRA, A. F. de S. da. Fonética sintática. Rio de Janeiro: Organização Simões, 1952.

TENANI, L. O bloqueio do sândi vocálico em PB e em PE: evidências da frase fonológica. In: Revista Organon: Estudos de fonologia e morfologia, v. 18, n. 36, Porto Alegre, UFRGS, 2004.

\section{NOTAS}

${ }^{1}$ Para esse grupo de fator, precisamos retirar da análise os fatores: vogal átona + tônica, vogal tônica + tônica, pois eles geraram knockouts, visto que não encontramos casos de aplicação da ditongação decrescente nesses contextos. Isso já era esperado, porque a ditongação decrescente envolve a união de uma vogal + uma semivogal. Dessa forma, para a segunda vogal da sequência se tornar glide, ela não pode ser acentuada. A retirada dos fatores explica a redução no número total de dados.

${ }^{2}$ Para esse grupo de fator, precisamos retirar da análise os fatores: vogal alta + não alta, não alta + /e/ ou /o/, /e/ ou /o/ final + alta, /e/ ou /o/ final + não alta, pois eles geraram knockouts, visto que não encontramos casos de aplicação da ditongação decrescente nesses contextos. A retirada dos contextos com vogal não alta na segunda posição era esperada, porque, para que a segunda vogal se torne glide, no caso da ditongação decrescente, ela precisa ser alta. A retirada dos fatores explica a redução no número total de dados.

${ }^{3}$ Consideramos, na codificação dos dados, a real produção dos fonemas vocálicos. Dessa forma, o /o/ encontrado no exemplo foi produzido como uma vogal alta pelo informante.

${ }^{4}$ Para esse grupo de fator, precisamos retirar da análise os fatores vogal anterior + central, posterior + central e vogais posteriores, pois eles geraram knockouts, visto que não encontramos casos de aplicação da ditongação decrescente nesses contextos. A retirada dos fatores explica a redução no número total de dados.

${ }^{5}$ Para esse grupo de fator, precisamos retirar da análise o fator acentos adjacentes, pois ele gerou knockouts, visto que não encontramos casos de aplicação da ditongação decrescente nesses contextos. Isso já era esperado, porque a ditongação decrescente necessita de uma vogal átona. Dessa forma, para a segunda vogal da sequência se tornar glide, ela não pode ser acentuada. A retirada dos fatores explica a redução no número total de dados. 
${ }^{6}$ Para esse grupo de fator, foi retirado o fator semivogal, pois gerou knockout, visto que não encontramos casos de aplicação da ditongação decrescente nesse contexto. A retirada do fator explica a redução no número total de dados.

Recebido em: 30/01/2017

Aceito em: 10/06/2017 